\title{
Advances in Thin Film Sensor Technologies for Engine Applications
}

Jih-Fen Lei

Army Research Laboratory

Lewis Research Center

Cleveland, Ohio

Lisa C. Martin and Herbert A. Will

Lewis Research Center

Cleveland, Ohio

Prepared for

Turbo Expo '97

cosponsored by the International Gas Turbine Institute and

the American Society of Mechanical Engineers

Orlando, Florida, June 2-5, 1997

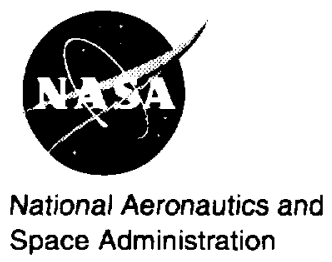


. 


\title{
ADVANCES IN THIN FILM SENSOR TECHNOLOGIES FOR ENGINE APPLICATIONS
}

\author{
Jih-Fen Lei \\ Army Research Laboratory \\ NASA Lewis Research Center \\ Cleveland, $\mathrm{OH} 44135$ \\ e-mail: jih-fen.lei@lerc.nasa.gov \\ Lisa C. Martin and Herbert A. Will \\ NASA Lewis Research Center \\ Cleveland, $\mathrm{OH} 44135$
}

\begin{abstract}
Advanced thin film sensor techniques that can provide accurate surface strain and temperature measurements are being developed at NASA Lewis Research Center. These sensors are needed to provide minimally intrusive characterization of advanced materials (such as ceramics and composites) and structures (such as components for Space Shuttle Main Engine, High Speed Civil Transport, Advanced Subsonic Transports and General Aviation Aircraft) in hostile, high-temperature environments, and for validation of design codes. This paper presents two advanced thin film sensor technologies: strain gauges and thermocouples. These sensors are sputter deposited directly onto the test articles and are only a few micrometers thick; the surface of the test article is not structurally altered and there is minimal disturbance of the gas flow over the surface. The strain gauges are palladium-13\% chromium based and the thermocouples are platinum-13\% rhodium vs. platinum. The fabrication techniques of these thin film sensors in a class 1000 cleanroom at the NASA Lewis Research Center are described. Their demonstration on a variety of engine materials, including superalloys, ceramics and advanced ceramic matrix composites, in several hostile, high-temperature test environments are discussed.
\end{abstract}

\section{INTRODUCTION}

In order to meet the urgent needs in aeronautic and aerospace research where stress and temperature gradients are high and aerodynamic effects need to be minimized, sensors in a thin film form are being developed at the NASA Lewis Research Center (LeRC) for surface measurement on various material systems. Sensors in a thin film form provide a minimally intrusive means of measuring surface parameters, such as strain or temperature, in hostile environments. They are needed in engine systems to evaluate advanced materials and components and to provide experimental verification of computational models. Unlike more conventional wire or foil sensors, thin films sensors do not necessitate any machining of the surface, thereby leaving intact the surfaces structural integrity. They are sputter deposited directly onto the surface and have thickness on the order of a few micrometers $(\mu \mathrm{m})$ which are many orders of magnitude thinner than wire. Thin film sensors, therefore, add negligible mass to the surface and create minimal disturbance of the gas flow over the surface. Consequently, thin film sensors have minimal impact on the thermal, strain and vibration patterns that exist in the operating environment.

The thin film thermocouple (TFTC) technology was originally developed for application to superalloys used in jet aircraft engine for temperature measurements up to $1000^{\circ} \mathrm{C}$ (Grant et al., 1981, Kreider et al., 1984). This technology was advanced through several NASA contracts and grants and extended to ceramic and intermetallic materials (Budhani et al., 1986, Holanda, 1992) used in the advanced jet engines. The work to develop and apply TFTCs at LeRC has been concentrated on platinum-13\% rhodium ( $\mathrm{Pt} 13 \mathrm{Rh})$ vs. platinum $(\mathrm{Pt})$ due to its high temperature capability. They have been applied to silicon nitride, silicon carbide, aluminum oxide (alumina), mullite, ceramic matrix composites, space shuttle thermal protection system tiles, and nickel aluminide in the temperature range from $1000-1500^{\circ} \mathrm{C}$ (Holanda, 1992, Holanda et al., 1993, Martin and Holanda, 1994, Martin and Will, 1996). TFTCs have undergone furnace tests as well as tests in harsh environments, including gas turbine (Grant et al., 1981) and hydrogen/oxygen engine environments under both low and high pressure conditions (Martin and Holanda, 1994), a high heat flux facility (Holanda, 1992, Holanda et al., 1993), and a diesel engine environment (Kim and Barrows, 1988).

Thin film strain gauge (TFSG) made of $\mathrm{NiCr}$ have been used successfully to $600^{\circ} \mathrm{C}$ in gas turbine engines and component rig dynamic strain testing (Grant et al. 1983, Stowell and Weise, 1983). The strain gauges developed at NASA LeRC are based on a newly developed alloy, 
palladium-13wt\%chromium (hereafter, $\mathrm{PdCr}$ ). This $\mathrm{PdCr}$ alloy was selected by United Technologies Research Center under a NASA contractto be the best candidate material for the high temperature strain gauge application (Hulse et al., 1987). It is structurally stable up to elevated temperatures and its apparent strain versus temperature characteristic is linear, repeatable and not sensitive to the rates of heating and cooling. Active development based on this new gauge alloy, $\mathrm{PdCr}$, is being pursued to extend its use in both dynamic and static strain testing on superalloy, ceramic and $\mathrm{CMC}$ components of engines and aircraft structures to $1100^{\circ} \mathrm{C}$ (Hulse et al., 1987, Lei, 1992, Kayser et al., 1992, Lei, 1995).

This paper describes efforts in the Sensors and Electronics Technology Branch of NASA LeRC in developing thin film strain gauges and thermocouples for high temperature applications on a range of materials. Sensor preparation techniques and procedures including thin film sputtering-deposition, electron beam evaporation, masking, and lead wire attachment techniques are discussed. The characteristics of the sensors and their testing results on various materials and in various environments are presented.

\section{SENSOR FABRICATION}

The fabrication of the thin film sensors is completed in a clean room to minimize possible contamination. The class 1000 cleanroom at the LeRC contains state-of-the-art facility including several thin film sputterdeposition and evaporation systems, wire bonding systems, etching systems, equipment for photolithography processes, and a surface profiler. The fabrication process of thin film sensor systems on a particular substrate material needs to be tailored to ensure good adhesion and no chemical interaction between the sensor and the substrate material. Figure 1 shows a schematic diagram of the thin film sensor layer structures on both electrically insulating and electrically conducting substrates. For an electrically conductive metal substrate, such as superalloy materials, an MCrAlY coating is first deposited onto the substrate by electron beam evaporation or by sputter deposition. $M$ can represent $\mathrm{Fe}, \mathrm{Co}, \mathrm{Ni}$, or a combination of $\mathrm{Co}$ and $\mathrm{Ni}$. With heat treatment, this coating forms a stable, adherent, electrically insulating alumina layer. An additional layer of alumina is sputter deposited or electron beam evaporated onto the surface to fill any pinholes or cracks that may be present in the grown oxide. Electrically conductive ceramic materials such as silicon carbide are thermally oxidized to form a stable, adherent silicon dioxide layer which is followed by another layer of alumina of the thickness needed to obtain the required insulation resistance. The thickness of the thermally grown oxide and sputter deposited alumina layers are approximately $2-3 \mu \mathrm{m}$ and $5-8 \mu \mathrm{m}$, respectively. The sensors are fabricated onto the alumina layer; in the case of electrically insulating materials such as silicon nitride, aluminum oxide and mullite, the sensor are fabricated directly onto its surface. For those applications that require a protective overcoat, a coating of alumina is deposited either by sputtering or evaporation onto the sensor to a thickness of approximately $2-3 \mu \mathrm{m}$.

\section{Basecoat and Overcoat}

Alumina is used as both the basecoat and overcoat for thin film sensor systems because it has the highest resistivity among all the dielectric materials. When deposited from a pure alumina source (99.9\%), an insulating alumina thin film has an electrical resistivity as high as that of the bulk materials $\left(5 \times 10^{7} \mathrm{ohm}-\mathrm{cm}\right.$ at $\left.1100^{\circ} \mathrm{C}\right)$. For a 120 ohm strain gauge to be useable to $1100^{\circ} \mathrm{C}$, an alumina basecoat with a thickness of $7 \mu \mathrm{m}$ or higher is needed to provide at least $0.1 \mathrm{Mohm}$ resistance-to-ground at all operating temperatures up to $1100^{\circ} \mathrm{C}$.
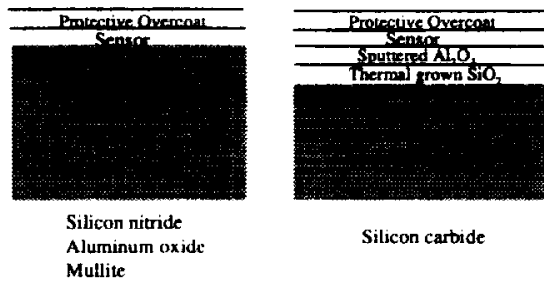

Mullite

Silicon carbide

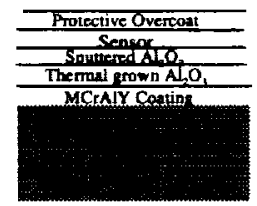

Superalloys

Figure 1. Schematic diagram of thin film sensors on various substrate materials.

To fabricate a dense and thick alumina layer with no pinholes or cracks, the substrate needs to be heated during sputtering to increase mobility of the depositing atoms and to minimize thermal stress. The alumina film is, therefore in extension during the deposition, and then in compression at room temperature with a level of stress high enough to compensate any expansion during use to the maximum temperature. It was found that $800-900 \mathrm{C}$ is the preferred substrate temperature range for depositing an alumina layer that is useful up to $1100^{\circ} \mathrm{C}$ (Kayser et al., 1992). This alumina film can be put down by either sputtering or evaporation. The sputtering process is very slow, taking approximately 50 hours to prepare a $6-8 \mu \mathrm{m}$ thick alumina film compared to only 20 minutes needed for the E-beam evaporation. The fabrication parameters for alumina films are listed in Table $I$.

\section{Thermocouples}

The thermocouples are patterned with stenciled shadow masks during sputter deposition of the Pt and Pt13Rh thin films. An adjacent heater is maintained at $400{ }^{\circ} \mathrm{C}$ during the sputter-deposition process. The sputtering parameters for $5 \mu \mathrm{m}$ thick Pt and Pt13Rh films are listed in Table I.

Table I. Thin film deposition conditions for Pt13Rh/Pt thermocouples (TC) and PdCr/Pt strain gauge (SG)

\begin{tabular}{|l|l|l|l|l|l|}
\hline MATERIAL & $\begin{array}{l}\text { TARGET } \\
\text { COMPOSITION }\end{array}$ & $\begin{array}{l}\text { POWER DENSITY } \\
\left(\mathrm{W} \mathrm{CM}^{-2}\right.\end{array}$ & DEPOSTION MODE & SUBSTRATE TEMP. & $\begin{array}{l}\text { THCKNESS } \\
(\mu \mathrm{M})\end{array}$ \\
\hline $\mathrm{P}$ (TC \&SG) & $\mathrm{Pt}$ & 1.94 & Magnetron & $400^{\circ} \mathrm{C}$ & 5 \\
\hline $\mathrm{Pt}-\mathrm{Rh}(\mathrm{TC})$ & $\mathrm{P} 13 \mathrm{wt} \% \mathrm{Rh}$ & 1.94 & Magnetron & $400^{\circ} \mathrm{C}$ & 5 \\
\hline $\mathrm{PdCr}(\mathrm{SG})$ & $\mathrm{Pd} 14 \mathrm{wt} \% \mathrm{Cr}$ & 1.94 & Diode & $25^{\circ} \mathrm{C}$ & 8 \\
\hline Alumina & $\mathrm{Al}_{2} \mathrm{O}_{3}$ & 3.44 & $\mathrm{R} . \mathrm{F}$ & $900^{\circ} \mathrm{C}$ & $6-8$ \\
\hline Alumina & $\mathrm{Al}_{2} \mathrm{O}_{3}$ & $\mathrm{E}-\mathrm{beam}$ & Evaporation & $900^{\circ} \mathrm{C}$ & $6-8$ \\
\hline
\end{tabular}




\section{Strain Gauge}

Figure 2a presents a dynamic strain gauge made of a $\mathrm{PdCr}$ thin film. The $\mathrm{PdCr}$ gauge is prepared first by sputter deposition of $\mathrm{PdCr}$ thin film of approximately $8 \mu \mathrm{m}$ thickness, then patterned using the photolithography technique and chemical etching with $\mathrm{FeCl}_{3}$. For static strain applications, a temperature compensator element platinum $(\mathrm{Pt})$ is adopted to minimize the temperature effect on the resistance change of the $\mathrm{PdCr}$. This is because $\mathrm{PdCr}$ has a higher (but constant) temperature coefficient of resistance than that allowed for a static strain gauge. The Pt element, $5 \mu \mathrm{m}$ thick, is located around the PdCr gauge grid and is connected to the adjacent arm of a Wheatstone bridge circuit to minimize the temperature effect (Lei et al., 1991) (Fig. 2b). The Pt compensator is patterned using a metal shadow mask during deposition. The sputtering parameters for both $\mathrm{PdCr}$ and $\mathrm{Pt}$ films are listed in Table I.

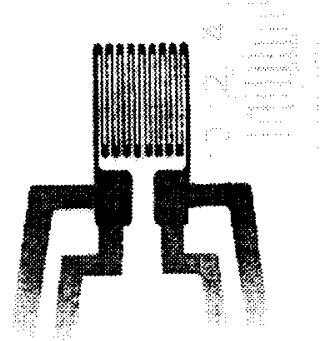

Pacr Gege to: Dynamic Stran

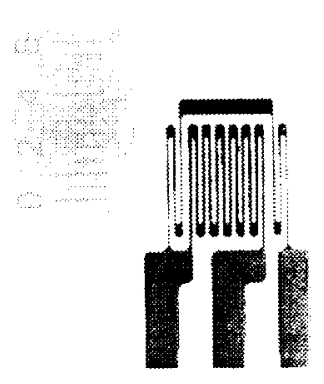

Pdorpl Gaye for Static strain
Figure 2. PdCr based thin film strain gauges. (a) dynamic strain gauge and (b) static strain gauge.

\section{Lead wire attachment}

The $75 \mu \mathrm{m}$ diameter leadwires which connect to the measurement circuits are attached to the thin films via the parallel gap welding process (Holanda et al., 1990). Leadwires made of Pt13Rh and Pt are used for Pt13Rh and Pt TFTC elements, respectively, and Pt leadwires are used for both $\mathrm{PdCr}$ and $\mathrm{Pt}$ strain gauge elements. The leadwires are secured onto the substrate by means of a high temperature ceramic cement.

\section{SENSOR CHARACTERISTICS AND TESTING Thermocouples}

TFTCs have been fabricated and tested on various substrate systems including nickel based superalloys, silicon nitride $\left(\mathrm{Si}_{3} \mathrm{~N}_{4}\right)$, silicon carbide ( $\mathrm{SiC})$, mullite and aluminum oxide $\left(\mathrm{Al}_{2} \mathrm{O}_{3}\right.$, ceramics, ceramic matrix composites (CMC), and intermetallics. The test conditions are summarized in Table II.

TFTCs on a nickel based superalloy have been tested up to $1100^{\circ} \mathrm{C}$ in conditions similar to, though not as severe as, the Space Shuttle Main Engine (SSME) high pressure fuel turbopump environment (Martin and Holanda, 1994). Sensors tested on flat panels at low pressure conditions proved to be highly adherent and durable. However, when TFTCs were tested on SSME turbine blades, Fig. 3, under high pressure, high temperature conditions, repeated stable thermal output was difficult to obtain. This may be attributed to poor contact between the thin films and leadwires. The TFTC output was unstable during changes in pressure; the vibrations of the facility during start up and shut down may have also disrupted contacts between the wire and film thereby resulting in unstable output.

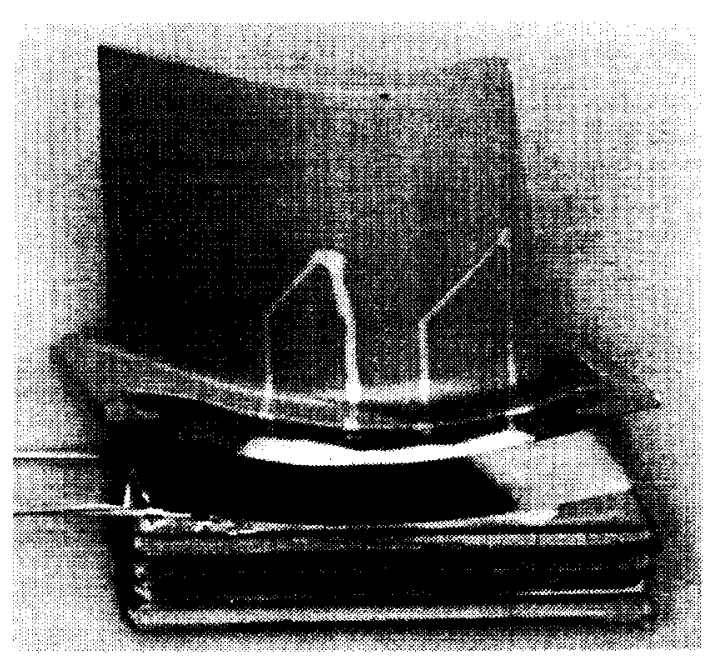

Figure 3. Pt13Rh/Pt Thin film thermocouples applied on space shuttle main engine turbine blade.

Table II. Summary of TFTC applications at NASA LeRC

\begin{tabular}{|c|c|c|c|}
\hline MATERIAL & GEOMETRY & TEST CONDITION & TEMPERATURE - TIME \\
\hline Nickel-based superalloy & flat plate & $\begin{array}{l}\text { Hydrogen-oxygen combustion pressures to } 4 \mathrm{MPa} \\
\text { atmosphere }\end{array}$ & 0 to $900-1000^{\circ} \mathrm{C}$ in five seconds, ten cycles \\
\hline Nickel-based superalloy & turbinc blades & $\begin{array}{l}\text { SSME type conditions; Hydrogen-oxygen combustion } \\
\text { pressures to } 16 \mathrm{MPa}\end{array}$ & 0 to $930^{\circ} \mathrm{C}$ in six seconds, three cycles \\
\hline $\mathrm{Al}_{2} \mathrm{O}_{3}$ \& Mullite & flat plate & air fumace & $\begin{array}{l}1000-1500^{\circ} \mathrm{C}, 150 \mathrm{hrs} \text { static and cycling test \& up } \\
\text { to } 2500^{\circ} \mathrm{C} / \mathrm{sec} \text { thermal shock- } 20 \text { cycles }\end{array}$ \\
\hline $\mathrm{Si}_{3} \mathrm{~N}_{4} \& \mathrm{SiC}$ & flat plate & air fumace & $\begin{array}{l}1000-1500^{\circ} \mathrm{C}, 150 \mathrm{hrs} \text { static and cycling \& up to } \\
2500^{\circ} \mathrm{C} / \mathrm{sec} \text { thermal shock-20 cycles }\end{array}$ \\
\hline HPZ/SiC CMC & hoop & burner rig with jet fuel pressure to $2 \mathrm{MPa}$ & $\begin{array}{l}\text { gas temp: } 1500^{\circ} \mathrm{C} \\
\text { surface temp: } 1100^{\circ} \mathrm{C}, 25 \text { hrs }\end{array}$ \\
\hline$\overline{\mathrm{SiC}} \mathrm{SiC} \mathrm{CMC}$ & flat plat \& cylinder & bumer rig with jet fuel pressure to $2 \mathrm{MPa}$ & $\begin{array}{l}\text { gas temp: } 1500^{\circ} \mathrm{C} \\
\text { surface temp: } 1100^{\circ} \mathrm{C}, 10 \mathrm{hrs}\end{array}$ \\
\hline
\end{tabular}


The TFTCs instrumented on ceramic materials were evaluated in ceramic tube air furnaces under steady state and thermal cycling modes up to 1000 to $1500{ }^{\circ} \mathrm{C}$ for times up to 150 hours at ambient pressures (Holanda, 1992, Holanda et al., 1993). No sensor failures occurred during this total test time. The resulting drift rate of the TFTCs varies with: (1) the absolute temperature level of the substrate material on which the TFTC is deposited; (2) the temperature gradient distribution between the thin film and the leadwire portion of the circuit; and (3) the film thickness and diameter of the leadwires. At temperatures greater than about $1250{ }^{\circ} \mathrm{C}$, drift rates rapidly increase as test temperature increases but varies for each substrate material. Selected drift rates of TFTCs on various materials and compared to that of wire TCs are tabulated in Fig. 4. The aluminum oxide and mullite had little visible surface deterioration after the tests, and there was very little degradation of the sensor structure. Silicon nitride and silicon carbide, however, exhibited visible surface changes at temperatures above about $1250^{\circ} \mathrm{C}$. The higher purity of these silicon-based materials reduced the amount of substrate surface oxidation and interfacial reactions that can contribute to sensor failure. TFTCs on silicon nitride and mullite also exhibited good durability to survive a 20 cycle test with a heating rate up to $2500^{\circ} \mathrm{C} / \mathrm{sec}$ (Holanda et al., 1993).

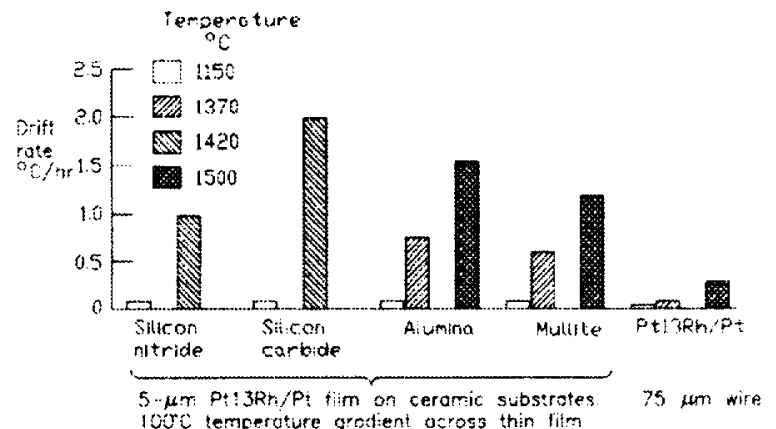

Figure 4. Drift rates for thin film thermocouples compared to that of wire thermocouples.

More recent applications of TFTCs have been concentrated on the evaluation of advanced CMC materials (Martin and Will, 1996) designed to meet propulsion capability goals of the Integrated High Performance Turbine Engine Technology (IHPTET) and High Speed Civil Transport (HSCT). A hoop made of hydridopolysilazane fiber/silicon carbide
(HPZ/SiC) CMC was instrumented with three TFTCs and tested in a burner rig that operates on jet fuel at pressure of 0.7 to $2 \mathrm{MPa}(100-300$ psi). The average gas stream temperature is approximately $1500^{\circ} \mathrm{C}$. A TFTC provided surface temperature data up to $1100{ }^{\circ} \mathrm{C}$ for over 25 hours. The eventual failure mechanism for the TFTCs was again due to the poor contacts between the thin film and the leadwires as well as the leadwires attachment on the $\mathrm{CMC}$ substrate material. Several $\mathrm{SiC} / \mathrm{SiC}$ CMC flat panels and cylinders are being instrumented with TFTCs and tested in the same facility. Improvements in the lead wire attachment technique are being addressed.

\section{Strain Gauges}

The advanced PdCr based TFSG is a much newer technology compared to the Pt13Rh/Pt TFTCs. Their applications in harsh environments have therefore been limited. They, however, have been fabricated and tested on various substrate systems including nickel-based superalloys, silicon nitride $\left(\mathrm{Si}_{3} \mathrm{~N}_{4}\right)$ and aluminum oxide $\left(\mathrm{Al}_{2} \mathrm{O}_{3}\right)$ ceramics, and $\mathrm{SiC} / \mathrm{SiC}$ ceramic matrix composites (CMC). The test conditions are summarized in Table III.

Depending on the application, whether for dynamic strain or static strain measurement, the requirements for a useful gauge may be different. For dynamic strain measurements during which the rate of change in strain is much larger compared with the rate of change in temperature even if the time period is long, the allowed apparent strain sensitivity of a gauge can be very high. The general requirements for a useful dynamic strain gauge are (1) its apparent strain sensitivity is less than 100 microstrain $(\mu \epsilon) /{ }^{\circ} \mathrm{C}$, and (2) its drift strain rate at use temperatures is less than $500 \mu \in$ /hour (Grant et al., 1983). On the other hand, for static strain measurement over long periods of time during which both the temperature and strain may vary, the allowed apparent strain and drift strain of a useful gauge are much lower than that for a dynamic strain gauge. For a required accuracy of $10 \%$ for static strain measurements in the range of $2000 \mu \mathrm{t}$, the total apparent strain and the drift strain should be smaller than $200 \mu \epsilon$, so as to be neglected, or repeatable within $200 \mu \epsilon$, so it can be corrected.

When connected to a Wheatstone bridge circuit in a quarter bridge configuration, the resulting apparent strain of a $\mathrm{PdCr}$ dynamic strain gauge is stable and repeatable between thermal cycles to $1100^{\circ} \mathrm{C}$ (Lei, 1995). The apparent strain sensitivity is approximately $85 \mu \epsilon / \mathrm{C}$ which is less than the required value of $100 \mu \in / \mathrm{C}$. The drift strain of the gauge at $1100 \mathrm{C}$ is also less than the required value of $500 \mu \mathrm{c} /$ hour. The resulting apparent strain characteristic of a $\mathrm{PdCr}$ static strain gauge connected to a

Table III. Summary of TFSG application at NASA LeRC

\begin{tabular}{|l|l|l|l|}
\hline MATERIAL & GEOMETRY & TEST CONDITION & TEMP-TIME \\
\hline $\begin{array}{l}\text { Nickel-based } \\
\text { superalloy }\end{array}$ & cantilever bar \& $125 \mu \mathrm{m}$ shim & air furnace \& heat flux arc lamp & up to $1100^{\circ} \mathrm{C} \&$ up to $1000{ }^{\circ} \mathrm{C} / \mathrm{sec}$ thermal shock \\
\hline $\mathrm{A}_{2} \mathrm{O}_{3}$ & cantilever bar & air furmace \& heat flux arc tamp & up to $1100^{\circ} \mathrm{C} \&$ up to $10000^{\circ} \mathrm{C} / \mathrm{sec}$ thermal shock \\
\hline $\mathrm{Si}_{3} \mathrm{~N}_{4}$ & flat plate \& turbine blade & air furnace and spin rig & up to $1100^{\circ} \mathrm{C}$, static and cycling under $\pm 2000 \mu$ \\
\hline $\mathrm{SiC} / \mathrm{SiC} \mathrm{CMC}$ & flat pancl & bumer rig with jet fuel pressure to $2 \mathrm{MPa}$ & gas temp: $1500^{\circ} \mathrm{C}$, surface temp: $1100^{\circ} \mathrm{C}$ \\
\hline
\end{tabular}


Wheatstone bridge circuit in a half bridge configuration is stable and repeatable within $+200 \mu \epsilon$ between thermal cycles to $1100 \mathrm{C}$ with a sensitivity less than $3.5 \mu \mathrm{E} / \mathrm{C}$ in the entire temperature range. The apparent strain of this $\mathrm{PdCr}$ compensated thin film gauge can be corrected to within $: 200 \mu \mathrm{\epsilon}$ if the uncertainty in temperature measurement is within 57 "C. This $\mathrm{PdCr}$ based gauge is stable and responds linearly to the mechanical loads even at $1050 \mathrm{C}$. Its strain sensitivity (or gauge factor) decreases only approximately $22 \%$ from room temperature to $1050 \mathrm{C}$ (1900 ${ }^{\circ} \mathrm{F}$ ) (Fig. 5).

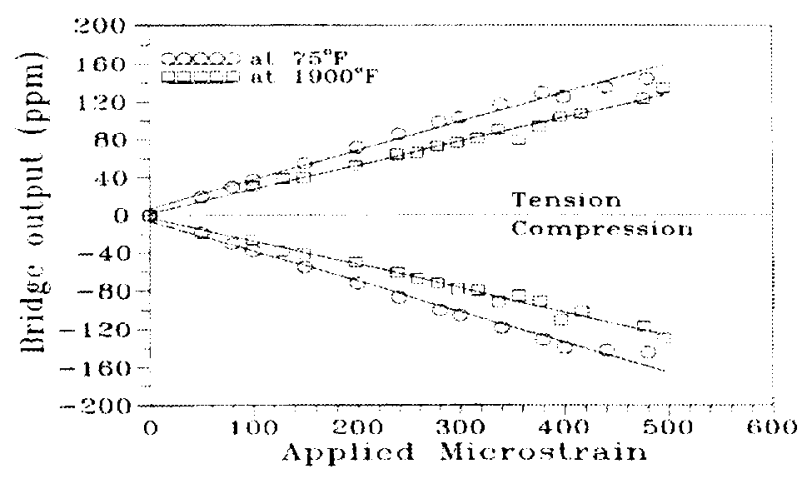

Figure 5. Mechanical response of a PdCr based strain gauge at both room temperature and at $1050^{\circ} \mathrm{C}\left(1900^{\circ} \mathrm{F}\right)$.

PdCr based TFSGs have been evaluated on various materials in the air furmace up to $1100^{\circ} \mathrm{C}$ and in a heat flux calibrator with high heating rates up to $1100^{\circ} \mathrm{C} / \mathrm{sec}$. Heat flux lamp currents from 30 to $400 \mathrm{amp}$ are used to generate heat fluxes from about 0.1 to $2 \mathrm{MW} / \mathrm{m}^{2}$ and a heating rates from about 2 to $1100^{\circ} \mathrm{C} / \mathrm{sec}$. Maximum temperature was $1100^{\circ} \mathrm{C}$. No sensor failures occurred after they were subjected to the maximum heat flux. These advanced $\mathrm{PdCr}$ dynamic gauges were also applied to an advanced turbine blade made of silicon nitride utilized in the IHPTET environment (Fig. 6). The gauge survive tests up to a maximum speed of $42500 \mathrm{rpm}$ and a fatigue tests under $\pm 2000 \mu \epsilon$ up to $1000^{\circ} \mathrm{C}$ for a million cycles. The gauges are now being applied to $\mathrm{SiC} / \mathrm{SiC} \mathrm{CMCs}$ components for HSCT and evaluated in a burner rig that operates on jet fuel at pressure of 0.7 to $2 \mathrm{MPa}(100-300 \mathrm{psi})$. The average gas stream temperature was approximately $1500{ }^{\circ} \mathrm{C}$, and the $\mathrm{CMC}$ surface temperature was approximately $1100^{\circ} \mathrm{C}$.

A weldable $\mathrm{PdCr}$ based TFSG was also developed by first fabricating the gauge on a metal shim, which is then transported and welded on the test article. It provides an option for applications where sputtering a gauge directly on a large test article is impossible or the installation of the gauges has to be done in the test field. A metal shim such as a $75 \mu \mathrm{m}$ thick Hastelloy-X should have a similar CTE to that of the substrate material. The apparent strain curve of a weldable gauge is similar to that of the gauge deposited directly on the substrate. The mechanical response of this weldable gauge is also similar to that of a directly-deposited gauge in that it is linear to the mechanical load and has no delay in transferring the strain (Lei, 1995).

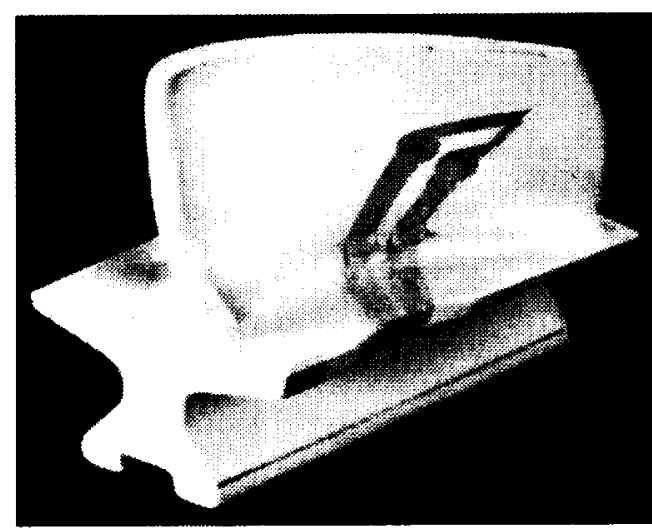

Figure 6. PdCr thin film dynamic strain gauge applied on a silicon nitride turbine blade'.

\section{SUMMARY AND FUTURE WORK}

Measurement techniques for propulsion systems are advanced through the development of thin film thermocouples and strain gauges. These thin film sensors have the advantage of providing minimally intrusive measurements. Thin film thermocouples, made of $\mathrm{Pt} 13 \mathrm{Rh} / \mathrm{Pt}$, have proven to be applicable to a range of materials and applications. They have been demonstrated on superalloys, ceramics, ceramic composites, and intermetallics. Data has been obtained in furnace testing, under high heat flux conditions, and in harsh engine environments. Thin film strain gauges based on a newly developed alloy, $\mathrm{PdCr}$, have been developed for both dynamic and static strain applications in the temperature range from room temperature to $1100 \mathrm{C}$. This is a 500 ${ }^{\circ} \mathrm{C}$ advance over the more conventional $\mathrm{NiCr}$ technology. A weldable strain gauge for applications where sputtering a gauge directly onto a large test article is impossible or the installation of the gauges has to been done in the test field has also been developed.

Future work will be concentrated on the improvements of the reliability and durability of these sensors in the high temperature, high pressure, high velocity gas stream environments. The lead wire attachment techniques to both the thin films and the substrate materials needs to be improved. A more protective coating to protect thin film sensors from erosion and catalytic reactions in these environments will also need to be addressed. The gaging techniques on the curved surface is an area of further investigation. Characterization of these thin film sensors on advanced materials such as CMCs will continue in order to establish a statistical database. In addition, the next generation of sensors that can be used to even higher temperatures $\left(>1200^{\circ} \mathrm{C}\right)$ will be explored to address the needs for advanced aeropropulsion research.

\section{ACKNOWLEDGMENTS}

The authors would like to acknowledge the invaluable assistance of Gerald A. Danzey, Keith F. Taylor, and Drago Androjna of NASA LeRC for the fabrication of the test specimens.

\footnotetext{
${ }^{1}$ Demonstrated by AlliedSignal Engine Co. under a DOE contract No. DEAC02-96-EE-50454 for DOE Ceramic Turbine Engine Demonstrate Project.
} 


\section{REFERENCES}

Budhani, R. C., Prakash, S. and Bunshah, R. F., 1986, "Thin Film Temperature Sensors for Gas Turbine Engines; Problems and Prospects", J. Vac. Sci. Technol. A, vol. 4, pp. 2609-2617, Noy.-Dec.

Grant, H. P., Przybyszewski, J. S. and Claing, R. G., 1981, "Turbine Blade Temperature Measurements Using Thin Film Temperature Sensors", PWA-5604-31, NASA CR-165201.

Grant, H. P., Przybyzewski, J. S., Anderson, W. L. and Claing, R. G., 1983,"Thin Film Strain Gauge Development Program", NASA CR174707.

Kayser, P., Godefroy, J. C., and Leca, L., 1992, "High Temperature Thin Film Strain Gauges", Eurosensors VI Conference Proceeding, October.

Kreider, K. G., Semancik, S., and Olson, C., 1984, "Advanced Thin Film Thermocouples", NBSIR 84-2949, National Bureau of Standards, NASA CR-175541.

Kim, S., and Barrows, R. F., 1988, "Prototype Thin Film Thermocouple/Heat Flux Sensor for a Ceramic-Insulated Diesel Engine", DOE/NASA/50162-1, NASA TM-100798.

Holanda, R., Kim, W. S., Pencil, E., Groth, M., and Danzey, G., 1990, "Attachment of Lead Wires to Thin Film Thermocouples Mounted on High Temperature Materials Using the Parallel Gap Welding Process", NASA TM-102442.

Holanda, R., Anderson, R. C., and Liebert, C. H., 1993,"Heat Flux Measurements on Ceramics with Thin Film Thermocouples", SEM Fall Conference Proceeding of Structural Testing Technology at High Temperature, p.78-87.

Holanda, R. ,1992, "Development of Thin Film Thermocouples on Ceramic Materials for Advanced Propulsion System Applications", 7th International Symposium on Temperature: Its Measurement and Control in Science and Industry, Toronto, Canada, April.
Hulse, C. O., Bailey, R. S., Grant. H.P., and Przybyzewski, J. S., 1987, "Development of a High Temperature Thin Film Static Strain Gauge", NASA CP-2493.

Lei, J. -F, Englund, D. R., and Croom, C., 1991, "The Temperature Compensation Technique for a PdCr Resistance Strain Gauge", SEM Fall Conference for Structural Testing Technology at High Temperature Proceeding, P. 190-96.

Lei, J. -F., 1992, "TECH SPOTLIGHT- PdCr Gages Measure Static Strain at High Temperature”, Advanced Materials \& Processes, p.58-59, May.

Lei, J.-F., 1995, "High Temperature Thin film Strain Gauge", British Society for Strain Measurement 1995 Annual Conference Proceeding, p.13-16.

Martin, L. C., and Holanda, R., 1994, "Applications of Thin Film Thermocouples for Surface Temperature Measurement", NASA TM106714.

Martin, L. C. and Will, H. A., 1996, "Testing of Thin Film Thermocouples on Ceramics Matrix Composites in a Burner Rig", NASP CP-10146, Paper 39.

Stowell, W. R. and Weise, R., 1983, "Application of Thin film Strain Gauges and Thermocouples for Measurement on Aircraft Engine Parts", AIAA-83-1292, AIAA/SAE/ASME $19^{\text {th }}$ Joint Propulsion Conference, Seattle, June. 


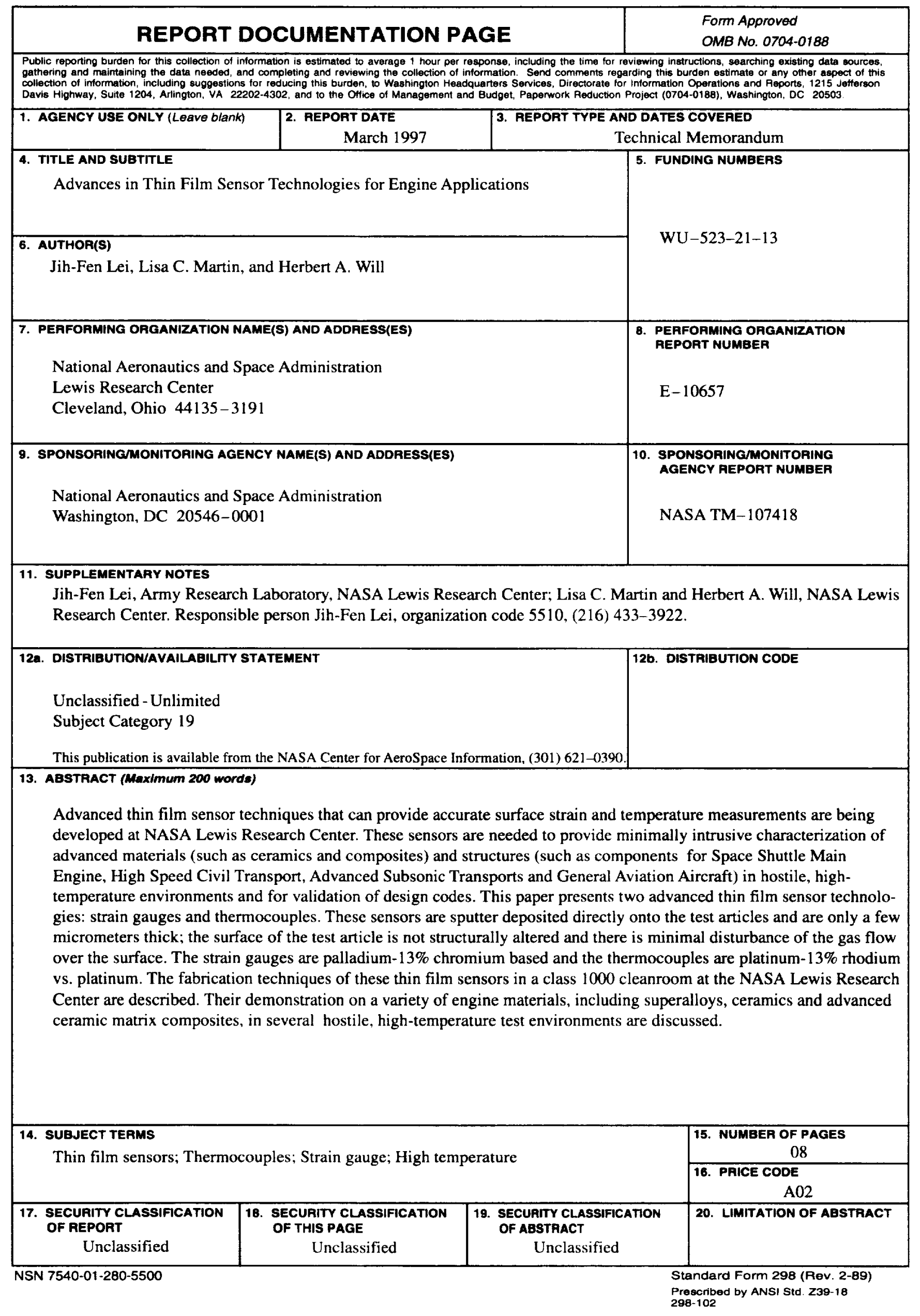

